\title{
Tourism Destination Marketing Using Facebook As A Promotional Tool
}

\author{
Shahnoor Rahman \\ Department of CommerceD.K.D.College, DergaonDist-Golaghat, Assam.
}

\begin{abstract}
Facebook is a social network for connecting people with those around them - friends, family, coworkers, or simply others with similar interests. Among the varied social media platforms, Facebook deserves a special mention with regard to promotion of a tourism destination. Facebook offers travel brands the ability to identify prospective travellers, communicate directly with users, engage with advocates and create branded experiences through advertisements and custom-developed Facebook applications. Facebook will also serve as a consumer market research tool for destinations to gather user insights, measure content engagement and crowd source ideas before bringing them to market. However, the biggest obstacle to promoting a destination on Facebook is budgeting and staffing. By sharing travel experiences on Facebook consumers are inspiring visitation through textual, photographic and video word-of-mouth recommendations. This article aims at highlighting how Facebook is used as a tool for promoting a tourism destination, strategies that can be effectively used, challenges and some success stories across the globe.
\end{abstract}

Key words: Facebook, tourism, destination marketing.

\section{INTRODUCTION}

Facebook is a social network for connecting people with those around them - friends, family, coworkers, or simply others with similar interests. Facebook started in 2004 as a closed community for college students (requiring users to sign up with a valid university email address) but has since expanded beyond that to schools, corporations, and any user across the world. Facebook allows users to connect and share information in a variety of ways. Facebook, launched on 4 February 2004, has over 750 million active users, 50\% of whom log on to the website daily (Facebook, 2011.) Businesses and organisations create and maintain an official presence on Facebook to engage with consumers.More and more people have been gradually changing the way they plan their holidays. Going to a travel agency's office is a thing of the past now. Vacations are planned right from their homes or offices, via the internet. They get to plan everything by themselves, seeing their convenience and preferences.People usually choose a destination on the basis of word of mouth or reviews of vacation experiences. This is backed by pricing of the entire trip. Online is the place to market a tourism business and for cashing in on the word of mouth, one needs to be on a social network like Facebook.

\section{LITERATURE REVIEW}

The creation and accessibility of the Internet have fundamentally changed how travellers access information, the way they plan for and book trips, and the way they share their travel experiences (Buhalis \& Law, 2008; Senecal \& Nantel, 2004; Xiang \& Gretzel, 2010). One significant development in the evolution of the Internet is the increasing prevalence of social media platforms that enable Internet users to collaborate, communicate and publish original content such as blogs, videos, wikis, reviews, or photos (Boyd and Ellison, 2008).Social media websites, facilitate consumer-generated content (CGC), and are widely used by online travellers' (Gretzel, 2006; White \& White, 2007). CGC and reviews sites such as Tripadvisor.com, are widespread and may even undermine the authority of traditional destination marketing organisations (DMOs) or conventional advertisements (Gretzel, 2006; Gretzel, Yuan, \& Fesenmaier, 2000; Rand, 2006). Among the varied social media platforms, Facebook deserves a special mention with regard to promotion of a tourism destination.

\section{METHODOLOGY}

This article has been prepared by studying data obtained from secondary sources including E books, journals and browsing the internet.

\section{OBJECTIVES}

1. To study how Facebook is used for promoting a tourism destination.

2. To study what marketing strategy is used for promoting a tourism destination using Facebook.

3. To study some challenges and success stories regarding using Facebook for promoting a tourism destination. 


\section{ANALYSIS AND FINDINGS \\ How Facebook is used for promoting a tourism destination-}

Facebook offers travel brands the ability to identify prospective travellers, communicate directly with users, engage with advocates and create branded experiences through advertisements and custom-developed Facebook applications. Facebook is the most powerful social media channel for tourism marketers because of the platform's purchasing process. The process of promoting a tourism destination on Facebook with the purpose of attracting more and more tourists to visit the destination is quite similar to the promotion of other businesses on the Facebook platform. The use of Facebook to promote a tourism destination on its platform requires the completion of several steps. The heart of the Facebook marketing platform is Facebook Pages. A Facebook Page is a brand's storefront and where a DMO (Destination Marketing Organisation) will be able to showcase its destination's most important images, select a vanity URL, list its business details and link to its website. Facebook Pages also allow a DMO or a tourism marketer to list upcoming events, map its location and feature photo and video galleries. The Facebook Page is where a DMO or the tourism marketer will generate connections and long-term relationships with its brand advocates (residents and past visitors) and attract potential visitors. Building a Facebook Page is simple, quick and free.To develop more engaging brand experiences, tourism marketers can develop or install Facebook Page Apps that will be located on a Facebook Page. Facebook Page Apps are available from third party application developers or can be custom developed to deliver highly engaging interactions. Popular Facebook Page Apps for destination pages include sign up forms for newsletters and vacation guides, contests and sweepstakes, co-op programs and integration with other social media channels. While some third party applications are available for free, customized Page apps require a web development investment.

\section{Marketing strategy -}

In order to properly market a destination on Facebook, a tourism marketer will need to have a sound understanding of who its core audience is by gender, age, geo location and interests. Whether it has in-depth visitor studies readily available or simply has website analytics to work with, and be sure to utilize the data it has available to clearly identify its audiences. Facebook will also serve as a consumer market research tool for destinations to gather user insights, measure content engagement and crowd source ideas before bringing them to market.The first task in developing a Facebook Marketing strategy is to clearly define the goals or objectives. As a DMO or tourism marketer, its goal is to drive visitation. However, consumers are look up to the organization to help them decide where they should go and what they should do. The marketer will need to balance the goals of both its organization and its prospective travellers to be effective on Facebook.

The importance of making the content engaging cannot be over overemphasized. $40 \%$ of Facebook users' time is spent in the News Feed and the more engaging the content is the more users a tourism marketer will reach. Impressions will generate and the longer the post will be featured in the News Feed. To achieve goals and provide value to the Facebook audience, the marketer will need to next develop a communication strategy to define its brand's voice, determine its message content and frequency of messaging. It must be kept in mind that status updates between 100 and 250 characters generate $60 \%$ more likes than longer posts. To steer the content strategy, web analytics need to be review to understand what content consumers are searching for and consuming. However, the content must not be limited to what is available on the tourism marketer's web site. It must determine the stories it wants to tell through status updates, photos or videos. Photo albums, pictures and videos generate $180 \%, 120 \%$ and $100 \%$ more engagement respectively.

Once the DMO or tourism marketer has begun deploying its destination's Facebook communication strategy, it must begin promoting its Facebook Page through other marketing channels and launch Facebook Ads. Mobile marketing is the fastest growing marketing trend and Facebook Marketers need to understand the importance of mobile marketing when developing a Facebook strategy. $68 \%$ of monthly active users access the platform through Facebook mobile products. When executing Facebook Ads or a promotion on Facebook, it must be ensured that the marketer is targeting mobile users and offering a mobile friendly experience.Social media never sleeps and neither should the Facebook strategy. Similar to successful search marketing campaigns, to run a successful Facebook platform the tourism marketer need to constantly optimize, develop content and run targeted advertising. By optimizing the content strategy to ensure that fresh, relevant and interesting content is being delivered into Facebook's News Feed the marketer must provide value to its fans. To reach target audiences it needs to amplify its posts and promote the brand using Facebook Ads and Sponsored Stories. Using Facebook's impressive level of ad targeting, destinations are able to hyper target users by location, age, gender, interests and Facebook connections. When properly administered, an always-on strategy increases the marketer's reach, generates brand impressions, creates word of mouth recommendations from family and friends and ultimately drives qualified audience to the site.Seasonal Facebook campaigns are an excellent way to drive awareness, engagement and visitation inspiration during pre-peak or need periods. By increasing the Facebook Ads budget and timing it with unique and innovative campaigns a tourism marketer or DMO can make sure to 
differentiate itself and gain the attention of travellers planning their next trip or vacation. To further incentivise its audience and build its following, it must think about layering in a contest, giveaway or sweepstakes.

\section{Challenges -}

The biggest obstacle to promoting a destination on Facebook is budgeting and staffing. While building a Facebook page is free, there are budget considerations including staffing, photo and video assessment, Facebook Ads, Facebook tab development and promotional contests and sweepstakes that need to be taken into consideration. Since users are able to engage with a tourism marketer's content, post on its timeline and message it 24/7, properly managing a Facebook Page is a time commitment. Social media users expect their feedback and questions to be responded to quickly, usually within few hours or they perceive the organization as unresponsive. Tourism marketers who are serious about their Facebook Page need to have dedicated staff to manage social media and/or utilize a marketing agency to provide support.

\section{Success stories -}

To properly track success on Facebook, tourism marketers need to focus on the performance of their Page's organic and paid reach, engagement and signals of intent to travel based on visitation inquires to the destination's website. Facebook provides robust analytics and key performing indicators for Facebook Pages and Facebook Ads. Some success stories from around the globe can be held up as examples for tourism marketers who have been struggling hard to promote their destinations but never looked at Facebook as an effective tool.

Scandinavia is a fairly unknown travel destination in the United States. Typically when American travellers visit Europe they travel to multiple countries. This has not been the case for Scandinavia even though transportation between the counties is convenient by car, train, ferry or flight. The "Go Scandinavian" campaign was designed to inspire and invite social media users to adopt the Scandinavian culture as their own. Facebook was positioned as the social media hub of the social media platform, with supporting channels including Twitter, Google+, Youtube, Flikr and Pinterest. By utilizing Facebook Ads and sponsored stories, to develop a core base of fans, the Visit Scandinavia Facebook page was able to quickly engage the geo targeted audiences with $74 \%$ of the user base falling within the 35-55 age demographic. At the peak of the campaign, the Facebook Page had an engagement rate of over $50 \%$ and the "Go Scandinavian" Facebook trivia sweepstakes generated 12,680 entries and 4,105 email addresses. Over the course of the three-month campaign 26M Facebook impressions were generated. The newly developed Facebook Page also experienced significant growth by generating 20,000 Facebook likes.

The Outer Banks is a string of narrow barrier islands off the coast of North Carolina in the U.S. A favourite East Coast vacation destination, summer is peak season for The Outer Banks. To insure that the destination remained at the top of the consumer mindset, The Outer Banks decided to leverage the destination's Facebook Page. The campaign targeted Facebook users aged 30 and older within East coast drive markets with interests in fishing, sailing, wind surfing, scuba diving, boating and beaches. The Outer Banks Facebook Page reached 6.6 million Facebook users, gained over 29,000 likes and generated 19.7 million impressions. During the campaign period, Facebook referred 3,690 visitors to The Outer Banks website and generated 610 vacation guide and e-newsletter requests at a $16.55 \%$ conversion rate. The campaign was awarded a Gold Adrian Award at the 2013 HSMAI Adrian Awards.

In India, Kerala Tourism recently organized two workshops in association with Facebook. Named as 'Travel Goes Social' the workshop and the social media campaign were conducted in the cities of Thiruvananthapuram and Kochi, to explore the potential of social media in the promotion of tourist destinations. The workshop at Thiruvananthapuram started with a talk on 'IT-enabling travel, tourism, and logistics' by IT expert Mr. Anand Parthasarathy. This was followed by lectures on 'How to use Facebook in travel industry' by Mr. Sachin Rao, head of small and medium business, Facebook (India) and Ms. Esme Lean, Facebook advertising specialist. The programme at Kochi focused on the theme 'Travel and tourism: leveraging social media and information technology.' Kerala is the only Indian state to have a Facebook Page to promote tourism in the state.

\section{CONCLUSION}

One of the most popular activities on Facebook is sharing travel experiences. By sharing travel experiences on Facebook consumers are inspiring visitation through textual, photographic and video word-ofmouth recommendations. Destination marketers have an opportunity to position themselves as a travel resource for consumers looking for travel ideas and inspiration on Facebook. Generating awareness, engagement and driving potential visitors further in the travel planning process are all benefits of maintaining an active Facebook Page. To amplify a Facebook Page's reach and impressions, destinations should utilize the Facebook Ads 
platform. Contests, sweepstakes and giveaways held on Facebook attract consumers and incentivise existing fans. In order to track the success of Facebook marketing, marketers need to measure multiple levels of metrics including Facebook Page Insights, Facebook Ads, and the impact Facebook referrals have on a destination's website.

\section{REFERENCES}

[1]. Boyd, D., \& Ellison, N. (2008). Social network sites: Definition, history, and scholarship. Journal of Computer-Mediated Communication, 210-230.

[2]. Buhalis, D., \& Law, R. (2008). Progress in information technology and tourism management: 20 years on and 10 years after the internet - the state of eTourism research. Tourism Management, 29, 607-623.

[3]. Department of Tourism, Government of Kerala, 2013

[4]. Facebook.com (2011). Statistics. Retrieved July 2011, from https://www. facebook.com/press/info.php? statistics

[5]. Forrester, Forrester Research Interactive Marketing Forecast By Industry, 2012 to 2017 (US)

[6]. Gretzel, U. (2006). Consumer generated content - trends and implications for branding. E-review of Tourism Research, 9-11.

[7]. Gretzel, U., Yuan, Y., \& Fesenmaier, D. (2000). Preparing for the new economadvertising strategies and change in destination marketing organizations. Journal of Travel Research, 149-156.

[8]. MMGY Global /Harrison Group (2013), Portrait of American Travelers

[9]. Rand, M. (2006). Online travel gets personal. Retrieved January 4, 2011, from http://www.forbes.com/2006/02/17/travelocity-orbitz-tripadvisor-in_mr_bow0217_inl.html

[10]. Senecal, S., \& Nantel, J. (2004). The influence of online product recommendations on consumers' online choices. Journal of Retailing, 159-169.

[11]. Facebook Stories, 2012, Sharing Life's Biggest Moments.

[12]. White, N., \& White, P. (2007). Home and away: Tourists in a connected world. Annals of Tourism Research, 88-104.

[13]. Why Use Social Media For Tourism Marketing?

[14]. http://www.marketingtourguide.com/public/192.cfm?sd=2 Accessed on March 15, 2014 